\title{
Addition of Cysteamine to a Serum-free Maturation Medium Enhances In Vitro Development of IVM-IVF Bovine Oocytes
}

\author{
Masaya Geshi1\#*, Curtis R. Youngs² and Takashi Nagai1 \\ ${ }^{1}$ Department of Animal Production, Tohoku National Agricultural Experiment Station, Morioka, \\ Iwate 020-0198, Japan \\ ${ }^{2}$ Department of Animal Science, Iowa State University, Ames, Iowa 50011-3150, USA \\ \#Present address: Department of Animal Reproduction, National Institute of Animal Industry, \\ Kukizaki, Ibaraki 305-0901, Japan
}

\begin{abstract}
Bovine cumulus-enclosed oocytes were matured in vitro (IVM) in PVA-HEPES-TCM199 supplemented with $0,0.5,5,50$ or $500 \mu M$ cysteamine for $24 \mathrm{~h}$ and fertilized in vitro (IVF). After removal of $\mathrm{cu}$ mulus cells, IVM-IVF oocytes were cultured in vitro for 8 days. Cysteamine had no effect on oocyte maturation or fertilization rates. In contrast, $5 \mu \mathrm{M}$ cysteamine in the maturation medium enhanced subsequent in-vitro development of IVM-IVF oocytes to the blastocyst stage. Glutathione (GSH) content of oocytes cultured in medium with 0 or $0.5 \mu M$ cysteamine was significantly lower than that of oocytes before culture. When oocytes were cultured in medium with 5, 50 or $500 \mu \mathrm{M}$ cysteamine, GSH content of oocytes remained constant $(5 \mu \mathrm{M})$ or was significantly increased (50 or $500 \mu \mathrm{M}$ ) compared with that of oocytes before culture. These results indicate that the addition of cysteamine to a serum-free maturation medium enhances the efficiency of in vitro production of bovine embryos by maintaining GSH content of IVM oocytes.
\end{abstract}

Key words: Cysteamine, Bovine, Oocyte, Serum-free maturation medium, Embryo development.

Embryos derived from in vitro matured (IVM) and in vitro fertilized (IVF) oocytes can be used for traditional animal genetic improvement as well as for biotechnological purposes. Recently, Grupen et al. [1] demonstrated that the addition of cysteamine to the maturation medium enhanced development of IVM-IVF porcine oocytes to the blastocyst stage by increasing the level of intracellular glutathione (GSH). Synthesis

Received: July 29, 1999

Accepted: September 8, 1999

*To whom correspondence should be addressed. of GSH during oocyte maturation occurs in mice [2], hamsters [3], pigs [4] and cattle [5-7]. After sperm penetration, GSH participates in sperm decondensation in parallel with oocyte activation, as well as in the transformation of the penetrated sperm head into the male pronucleus [2, 3, 8-10]. In addition, GSH is known to play an important role in protecting the cell from oxidative damage $[11,12]$.

Enhanced development of bovine IVM-IVF embryos following the addition of cysteamine to a maturation medium containing serum has been reported $[5,6]$. However, the use of fetal bovine serum in those experiments precludes an understanding of the mechanism through which cysteamine promoted the increased development of embryos, because serum is undefined and contains many constituents in varying concentrations, and data interpretation is therefore obscured. The use of a chemically defined culture medium (without undefined sera or other components) to evaluate the effect of a compound such as cysteamine is necessary for a full understanding of its mechanism of action.

The purpose of this study was to determine the effect of the addition of cysteamine to a serum-free maturation medium on GSH content of IVM bovine oocytes, and in vitro preimplantation development of in vitro produced embryos.

\section{Materials and Methods}

In vitro maturation

Bovine ovaries were obtained from a slaughterhouse and were transported to the laboratory in sterile $0.9 \%$ $\mathrm{NaCl}$ solution at $37^{\circ} \mathrm{C}$. Oocytes were aspirated from follicles ( 3 to $6 \mathrm{~mm}$ in diameter) with an 18 gauge needle attached to a disposable syringe. Selected cumulus- 
enclosed oocytes were washed three times in phosphate buffered saline containing $1 \mathrm{mg} / \mathrm{ml}$ polyvinyl alcohol (PVA, Sigma, St. Louis, MO, USA) and were cultured at $38.5^{\circ} \mathrm{C}$ for 22 to $24 \mathrm{~h}$ in $50 \mu \mathrm{l}$ of $25 \mathrm{mM}$ HEPES-buffered TCM-199 (Sigma) containing $1 \mathrm{mg} / \mathrm{ml}$ PVA, $20 \mu \mathrm{g} / \mathrm{ml}$ porcine follicle stimulating hormone (Sigma), $100 \mathrm{IU} / \mathrm{ml}$ penicillin (Sigma), $0.1 \mathrm{mg} / \mathrm{ml}$ streptomycin (Sigma) and 0 (control), $0.5,5,50$, or $500 \mu \mathrm{M}$ of cysteamine (Sigma) under mineral oil (Sigma) in an atmosphere of $5 \% \mathrm{CO}_{2}$ in air. Each drop of medium contained approximately 10 oocytes.

\section{In vitro fertilization}

After thawing of frozen semen for 15 seconds in $37^{\circ} \mathrm{C}$ water, spermatozoa were washed twice by centrifugation at $600 \mathrm{~g}$ for $5 \mathrm{~min}$ in Brackett \& Oliphant's medium (BO medium) [13] that had been modified by excluding bovine serum albumin (BSA) and adding $10 \mathrm{mM}$ caffeine (Sigma) (caffeine-BO medium). The sperm pellet was resuspended in caffeine-BO medium at a concentration of $1 \times 10^{7} \mathrm{cells} / \mathrm{ml}$ and then diluted with an equal volume of $\mathrm{BO}$ medium containing $20 \mathrm{mg} / \mathrm{ml}$ crystallized BSA (Sigma) and $15 \mu \mathrm{g} / \mathrm{ml}$ heparin (ICN Biochemicals, Cleveland, $\mathrm{OH}, \mathrm{USA}$ ). After maturation culture, the oocytes were washed twice in $\mathrm{BO}$ medium containing 7.5 $\mu \mathrm{g} / \mathrm{ml}$ heparin, $5 \mathrm{mM}$ caffeine and $10 \mathrm{mg} / \mathrm{ml}$ crystallized BSA. The oocytes were then transferred into $0.1 \mathrm{ml}$ drops of sperm suspension (approximately 10 oocytes/ drop) under mineral oil and incubated for $6 \mathrm{~h}$ at $38.5^{\circ} \mathrm{C}$ in $5 \% \mathrm{CO}_{2}$ in air.

\section{Culture of embryos}

After a $6 \mathrm{~h}$ insemination, cumulus cells were removed using a capillary pipette and the cumulus-free embryos were transferred to $50 \mu \mathrm{l}$ drops of CR1aa medium [14] under mineral oil. Oocytes were cultured at $38.5^{\circ} \mathrm{C}$ in $5 \% \mathrm{CO}_{2}, 5 \% \mathrm{O}_{2}, 90 \% \mathrm{~N}_{2}$. Embryos were cultured for 5 days, and the medium was replaced with an identical medium supplemented with $5.56 \mathrm{mM}$ glucose and then cultured for an additional 3-day culture period. The initial development of embryos was evaluated at $54 \mathrm{~h}$ after insemination, and development of embryos to the blastocyst stage was assessed on day 8 (day $0=$ insemination). The experiment was repeated 7 times.

\section{Assessment of maturation and fertilization rates}

The maturation rate was examined $24 \mathrm{~h}$ after maturation culture and the fertilization rate was examined 10 to $12 \mathrm{~h}$ after insemination. The oocytes were fixed for 24 to $48 \mathrm{~h}$ in ethanol:acetic acid $(3: 1, v / v)$, stained with $1 \%$ aceto-orcein and evaluated microscopically. Oo- cytes that had 1 set of male and female pronuclei and 1 sperm tail in the ooplasma were considered to be fertilized normally.

\section{Assay of GSH}

Oocytes before and after maturation culture in medium with $0,0.5,5,50$ or $500 \mu \mathrm{M}$ cysteamine were used for the assay of GSH content. All oocytes were denuded and washed 5 times in saline containing $3 \mathrm{mg} /$ $\mathrm{ml}$ polyvinyl pyrrolidone (PVP; Sigma). Groups of 50 oocytes in $5 \mu \mathrm{l}$ of distilled water (DW) containing $3 \mathrm{mg} /$ $\mathrm{ml}$ PVP were transferred to $1.5 \mathrm{ml}$ microcentrifuge tubes, and $5 \mu \mathrm{l}$ of $1.25 \mathrm{M} \mathrm{H}_{3} \mathrm{PO}_{4}$ was added. Then the samples were centrifuged at $2000 \mathrm{~g}$ for $5 \mathrm{~min}$ and frozen at $-80^{\circ} \mathrm{C}$ until assayed. The GSH content of oocytes was determined by the DTNB-GSSG reductase recycling assay according to Funahashi et al. [15]. Briefly, $700 \mu \mathrm{l}$ of $0.33 \mathrm{mg} \mathrm{NADPH} / \mathrm{ml}$ in $0.2 \mathrm{M}$ sodium phosphate buffer containing $10 \mathrm{mM}$ EDTA (stock buffer, pH 7.2), $100 \mu \mathrm{l}$ of $6 \mathrm{mM}$ 5,5'-dithiobis-2-nitrobenzoic acid (DTNB; Sigma) in the stock buffer, and $190 \mu \mathrm{l}$ of DW was added with mixing into the microcentrifuge tube. Ten $\mu \mathrm{l}$ of $250 \mathrm{IU}$ glutathione reductase/ml (Sigma) were added with mixing to initiate the reaction. The absorbance was monitored continuously at $412 \mathrm{~nm}$ with a spectrophotometer (Hitachi, Tokyo, Japan) for $3 \mathrm{~min}$, with readings recorded every $0.5 \mathrm{~min}$. Glutathione standards ( 0.1 to $1.0 \mathrm{nmol}$ ) and a sample blank lacking GSH were also assayed. The amount of GSH was determined according to Calvin et al. [2].

\section{Statistical analysis}

Statistical analyses were carried out by repeated measures one-way analysis of variance (ANOVA) and Fisher's protected least significant difference test using STATVIEW (Abacus Concepts., Inc., Berkeley, CA, USA). Data are presented as percentages or means with standard errors. All percentage data were subjected to arc sine transformation before statistical analysis.

\section{Results}

In 5 independent experiments, 497 oocytes were examined at $24 \mathrm{~h}$ after IVM to assess maturation rates in all treatments. In addition, in 4 independent experiments, 432 oocytes were examined 10 to $12 \mathrm{~h}$ after insemination to assess fertilization rates in all treatments. There were no differences in maturation and fertilization rates among treatments (Tables $1 \& 2$ ). However, a significantly higher $(P<0.05)$ percentage of IVF oocytes 
Table 1. Effect of cysteamine concentration on the maturation of bovine oocytes cultured for $24 \mathrm{~h}$ in vitro

\begin{tabular}{cccc}
\hline $\begin{array}{c}\text { Cysteamine } \\
(\mu \mathrm{M})\end{array}$ & $\begin{array}{c}\text { No. of } \\
\text { replicates }\end{array}$ & $\begin{array}{c}\text { No. of oocytes } \\
\text { examined }\end{array}$ & $\begin{array}{c}\% \pm \text { SE of } \\
\text { matured oocytes a }\end{array}$ \\
\hline 0 & 5 & 101 & $73.8 \pm 4.8$ \\
0.5 & 5 & 96 & $80.5 \pm 3.2$ \\
5 & 5 & 106 & $74.7 \pm 1.6$ \\
50 & 5 & 101 & $77.4 \pm 5.8$ \\
500 & 5 & 93 & $72.3 \pm 4.0$ \\
\hline
\end{tabular}

a Oocytes matured to metaphase-II.

Table 2. Effect of cysteamine concentration in the maturation medium on in vitro fertilization of bovine oocytes

\begin{tabular}{cccccc}
\hline \multirow{2}{*}{$\begin{array}{c}\text { Cysteamine } \\
(\mu \mathrm{M})\end{array}$} & \multirow{2}{*}{$\begin{array}{c}\text { No. of } \\
\text { replicates }\end{array}$} & \multirow{2}{*}{$\begin{array}{c}\text { No. of oocytes } \\
\text { examined }\end{array}$} & \multicolumn{3}{c}{$\% \pm$ SE of oocytes } \\
\cline { 4 - 6 } & & & $\geq \mathrm{M}-\mathrm{II}{ }^{\mathrm{a}}$ & penetrated $^{\mathrm{b}}$ & fertilized normally $^{\text {ac }}$ \\
\hline 0 & 4 & 85 & $82.6 \pm 5.5$ & $71.5 \pm 6.5$ & $53.9 \pm 5.8$ \\
0.5 & 4 & 88 & $90.6 \pm 3.5$ & $76.5 \pm 8.8$ & $57.0 \pm 4.4$ \\
5 & 4 & 86 & $90.9 \pm 2.4$ & $78.5 \pm 3.6$ & $51.7 \pm 7.3$ \\
50 & 4 & 88 & $87.6 \pm 3.9$ & $75.6 \pm 8.7$ & $49.9 \pm 7.0$ \\
500 & 4 & 85 & $81.3 \pm 3.7$ & $87.8 \pm 2.9$ & $53.3 \pm 10.0$ \\
\hline
\end{tabular}

a Oocytes reached to metaphase-II (M-II) or more advanced stages, fixed 10 to $12 \mathrm{~h}$ after in vitro insemination. ${ }^{b}$ Percentage of penetrated oocytes (possessed 1 or more sperms in the ooplasma) calculated per $\geq \mathrm{M}$-II oocyte. c Percentage of normally fertilized oocytes (possessed 1 set of male and female pronuclei and a sperm tail in the ooplasma) calculated per $\geq \mathrm{M}$-II oocyte.

Table 3. Effect of cysteamine concentration in the maturation medium on subsequent in vitro development of IVM-IVF bovine oocytes

\begin{tabular}{cccccc}
\hline \multirow{2}{*}{$\begin{array}{c}\text { Cysteamine } \\
(\mu \mathrm{M})\end{array}$} & $\begin{array}{c}\text { No. of } \\
\text { replicates }\end{array}$ & $\begin{array}{c}\text { No. of oocytes } \\
\text { examined }\end{array}$ & \multicolumn{2}{c}{$\% \pm$ SE of embryos developing to } \\
\cline { 4 - 6 } & & $\geq 2$-cell a & $\geq 6$-cell ${ }^{\mathrm{b}}$ & blastocyst $^{\mathrm{c}}$ \\
\hline 0 & 7 & 263 & $64.3 \pm 5.0$ & $37.2 \pm 3.3$ & $19.7 \pm 1.6^{\mathrm{d}}$ \\
0.5 & 7 & 261 & $60.9 \pm 4.2$ & $39.4 \pm 3.8$ & $21.7 \pm 2.9^{\mathrm{de}}$ \\
5 & 7 & 252 & $63.4 \pm 3.0$ & $41.2 \pm 3.4$ & $28.3 \pm 2.4^{\mathrm{e}}$ \\
50 & 7 & 260 & $66.0 \pm 2.1$ & $39.6 \pm 2.3$ & $21.9 \pm 3.3^{\mathrm{de}}$ \\
500 & 7 & 268 & $63.3 \pm 3.6$ & $37.0 \pm 2.6$ & $15.4 \pm 2.5^{\mathrm{d}}$ \\
\hline
\end{tabular}

a Embryos developing to the 2-cell stage or more advanced stages, observed $54 \mathrm{~h}$ after in vitro insemination. b Embryos developing to the 6-cell stage or more advanced stages, observed $54 \mathrm{~h}$ after in vitro insemination. ' Embryos developing to the blastocyst stage or more advanced stages, observed 8 days after in vitro insemination. de Means with different superscripts are significantly different $(\mathrm{P}<0.05)$.

matured in the medium containing $5 \mu \mathrm{M}$ cysteamine developed to the blastocyst stage at day 8 than those matured in medium with 0 (control) or $500 \mu \mathrm{M}$ cysteamine (Table 3).

The GSH content of oocytes before and after a $24 \mathrm{~h}$ maturation culture in medium containing $0,0.5,5,50$ or $500 \mu \mathrm{M}$ cysteamine is shown in Table 4. The GSH content of oocytes cultured in medium with 0 or $0.5 \mu \mathrm{M}$ cysteamine was significantly lower $(P<0.05)$ than that of GV stage oocytes (before culture). When cultured in medium with $5 \mu \mathrm{M}$ cysteamine, the GSH content of oocytes was similar to that of GV stage oocytes. The GSH content of oocytes cultured in medium with 50 or $500 \mu \mathrm{M}$ cysteamine was significantly higher $(\mathrm{P}<0.05)$ than that of other groups. 
Table 4. Effect of maturation with various levels of cysteamine on the GSH content of bovine oocyte cultured for $24 \mathrm{~h}$ in vitro

\begin{tabular}{cccc}
\hline $\begin{array}{l}\text { Culture } \\
\text { Period }\end{array}$ & $\begin{array}{c}\text { Concentration of } \\
\text { cysteamine }(\mu \mathrm{M})\end{array}$ & $\begin{array}{c}\text { No. of } \\
\text { replicates }\end{array}$ & $\begin{array}{c}\text { GSH content of oocyte } \\
\text { (pmol/oocyte) }\end{array}$ \\
\hline $0 \mathrm{~h}(\mathrm{GV})$ & $0^{*}$ & 3 & $6.863 \pm 0.187^{\mathrm{a}}$ \\
$24 \mathrm{~h}$ & 0 & 3 & $5.493 \pm 0.419^{\mathrm{b}}$ \\
$24 \mathrm{~h}$ & 0.5 & 3 & $5.000 \pm 0.070^{\mathrm{b}}$ \\
$24 \mathrm{~h}$ & 5 & 3 & $7.717 \pm 0.710^{\mathrm{a}}$ \\
$24 \mathrm{~h}$ & 50 & 3 & $10.660 \pm 0.208^{\mathrm{c}}$ \\
$24 \mathrm{~h}$ & 500 & 3 & $18.357 \pm 0.180^{\mathrm{d}}$ \\
\hline
\end{tabular}

${ }^{*}$ Oocytes not placed into maturation culture were at the germinal vesicle (GV) stage. ${ }^{a-d}$ Means with different superscripts are significantly different $(\mathrm{P}<0.05)$.

\section{Discussion}

The results of this study show that the addition of 5 $\mu \mathrm{M}$ cysteamine to a serum-free maturation medium is effective at maintaining GSH content of IVM bovine oocytes at the same level as GV oocytes and for enhancing subsequent in vitro development of treated oocytes to the blastocyst stage.

Grupen et al. [1] reported that the addition of $500 \mu \mathrm{M}$ cysteamine to maturation medium enhanced development of IVM-IVF porcine oocytes to the blastocyst stage. De Matos et al. [5] reported that the addition of $100 \mu \mathrm{M}$ cysteamine to a maturation medium containing fetal calf serum did not enhance maturation, fertilization or cleavage rates but did enhance the blastocyst formation rate of bovine oocytes. A similar result was obtained in our study, where addition of cysteamine to a serum-free maturation medium did not influence maturation or fertilization rates. However, use of $5 \mu \mathrm{M}$ cysteamine enhanced subsequent development of IVM-IVF oocytes to the blastocyst stage, whereas low $(0.5 \mu \mathrm{M})$ or high (50 or $500 \mu \mathrm{M}$ ) concentrations of cysteamine did not enhance development. The optimal concentration (5 $\mu \mathrm{M})$ of cysteamine in our serum-free maturation medium was lower than that $(100 \mu \mathrm{M})$ reported by de Matos et al. in their serum-containing maturation medium [5]. The reason for the discrepancy with respect to the effective concentration of cysteamine on the development of oocytes to the blastocyst stage is not clear. The intracellular glutathione level of bovine oocytes matured in vitro in our serum-free maturation medium with $5 \mu \mathrm{M}$ cysteamine is similar to those reported by de Matos et al. in their serum containing maturation medium with $100 \mu \mathrm{M}$ cysteamine $[5,6]$. Therefore, the use of serumfree maturation medium in our experiments is a likely reason for this difference.

GSH is synthesized throughout in vitro maturation of murine [2], hamster [3], porcine [4] and bovine [5-7] oocytes. The addition of cysteine, cysteamine and $\beta$ mercaptoethanol to maturation medium containing follicular fluid and/or serum stimulates GSH synthesis during in vitro maturation of porcine $[4,16]$ and bovine $[5,6]$ oocytes. The results of our study are in agreement with the findings of de Matos et al. [5, 6], except that the effective concentration of cysteamine was different. Miyamura et al. [7] reported that the GSH concentration in bovine oocytes was increased during in vitro maturation when oocytes were cultured in a medium supplemented with serum. However, in the present study, the GSH content of bovine oocytes matured in vitro in serum-free medium with 0 or $0.5 \mu \mathrm{M}$ cysteamine was decreased when compared to that of GV oocytes. The addition of more than $5 \mu \mathrm{M}$ cysteamine to maturation medium increased or left unchanged the GSH content of bovine oocytes after a $24 \mathrm{~h}$ maturation. Yamauchi et al. [16] reported that when porcine cumulus-oocyte complexes were cultured in maturation medium containing porcine follicular fluid, the GSH content of oocytes significantly decreased during maturation. De Matos et al. [6] reported that the amount of GSH in the oocytes varies from experiment to experiment due to different oocyte qualities in the batches, and Yoshida et al. [4] reported that the composition of maturation medium affects the GSH concentration in pig oocytes. Therefore, differences in culture media and oocyte quality are likely to account for these somewhat inconsistent results.

GSH is known to have important roles in maintaining the redox state of cells and in protecting cells against the harmful effects of oxidative injuries [11, 12]. However, the antioxidant capacity is not unlimited, and the 
pool of reduced thiols becomes rapidly exhausted while disulfide oxidation products accumulate [17]. The beneficial effects of low molecular weight thiol compounds on the development of bovine 4- to 8-cell embryos to the blastocyst stage $[18,19]$ is known to be accompanied by an increase of intracellular glutathione levels [20]. In addition, it has been reported [21] that coculture cells such as cumulus cells take up cystine and produce cysteine for synthesis of glutathione in embryos, as well as promoting synthesis of thiols which embryos can use. Therefore, it was suggested that the effect of cysteamine in maturation medium is to reduce cystine to cysteine and to promote the uptake of cysteine in oocytes and/or cumulus cells, resulting in stable or increasing levels of GSH in the matured oocytes and a subsequent increase in the number of embryos that develop to the blastocyst stage.

It is concluded that maintaining levels of intracellular GSH in bovine oocytes, by culturing with cysteamine during in vitro maturation, will provide oocytes with favorable intracellular conditions to support embryonic development to the blastocyst stage in vitro.

\section{Acknowledgement}

We are grateful to Dr. N. Yamauchi for specific helpful suggestions on the assay of GSH, and we thank Mrs. E. Yamauchi for technical assistance. Funding from the Japanese Ministry of Agriculture, Forestry and Fisheries is gratefully acknowledged.

Journal Paper No. J-18519 of the lowa Agriculture and Home Economics Experiment Station, Ames, Project 2942, a contribution to Regional Research Project W171 Germ Cell and Embryo Development and Manipulation for the Improvement of Livestock.

\section{References}

1) Grupen, C.G., Nagashima, H. and Nottle, M.B. (1995): Cysteamine enhances in vitro devel opment of porcine oocytes matured and fertilized in vitro. Biol. Reprod., 53, 173-178.

2) Calvin, H.I., Grosshans, K. and Blake, E.J . (1986): Estimation and manipulation of glutathione levels in prepuberal mouse ovaries and ova: relevance to sperm nucleus transformation in the fertilized egg. Gamete Res., 14, 265-275.

3) Perreault, S.D., Barbee, R.R. and Slott, V.I. (1988): Importance of glutathione in the acquisition and maintenance of sperm nuclear decondensing activity in maturing hamster oocytes. Dev. Biol., 125, 181-186.

4) Yoshida, M., Ishigaki, K., Nagai, T., Chikyu, M. and Pursel, V.G. (1993): Glutathione concentration dur- ing maturation and after fertilization in pig oocytes: relevance to the ability of oocytes to form male pronucleus. Biol. Reprod., 49, 89-94.

5) de Matos, D.G., Furnus, C.C., Moses, D.F. and Baldassarre, H. (1995): Effect of cysteamine on glutathione level and devel opment of bovine oocyte matured in vitro. Mol. Reprod. Dev., 42, 432-436.

6) de Matos, D.G., Furnus, C.C., Moses, D.F., Martinez, A.G. and Matkovic, M. (1996): Stimulation of glutathione synthesis of in vitro matured bovine oocytes and its effect on embryo development and freezability. Mol. Reprod. Dev., 45, 451-457.

7) Miyanuma, M., Yoshida, M., Hamano, S. and Kuwayama, M. (1995): Glutathione concentration during maturation and fertilization in bovine oocytes. Theriogenology, 43, 282 (abstr.).

8) Perreault, S.D., Wolff, R.A. and Zirkin, B.R. (1984): The role of disulfide bond reduction during mammalian sperm nuclear decondensation in vivo. Dev. Biol., 101, 160-167.

9) Yoshida, M., Ishigaki, K. and Pursel, V.G. (1992): Effect of maturation media on male pronuclear formation in pig oocytes matured in vitro. Mol. Reprod. Dev., 31, 68-71.

10) Yoshida, M. (1993): Role of glutathione in the maturation and fertilization of pig oocyte in vitro. Mol. Reprod. Dev., 35, 76-81.

11) Lim, J .M., Liou, S.S. and Hansel, W. (1996): Intracytoplasmic glutathione concentration and the role of $\beta$-mercaptoethanol in preimplantation development of bovine embryos. Theriogenology, 46, 429-439.

12) Meister. A. (1983): Selective modification of glutathione metabolism. Science, 220, 472-477.

13) Brackett, B.G. and Oliphant, G. (1975): Capacitation of rabbit spermatozoa in vitro. Biol. Reprod., 12, 260274.

14) Rosenkrans, J r. C.F., Zeng, G.Q., McNamara, G.T., Schoff, P.K. and First, N.L. (1993): Development of bovine embryos in vitro as affected by energy substrates. Biol. Reprod., 49, 459-462.

15) Funahashi, H., Cantley, T.C., Stumpf, T.T., Terlouw, S.L. and Day, B.N. (1994): In vitro development of in vitro-matured porcine oocytes following chemical activation or in vitro fertilization. Biol. Reprod., 50, 1072-1077.

16) Yamauchi, N. and Nagai, T. (1999): Male pronuclear formation in denuded porcine oocytes after in vitro maturation in the presence of cysteamine. Biol. Reprod., 61, 828-833.

17) Del Corso, A., Cappiello, M. and Mura, U. (1994): Thiol dependent oxidation of enzymes: The last chance against oxidative stress. Int. J . Biochem., 26, 745750.

18) Geshi, M., Yonai, M., Sakaguchi, M. and Nagai, T. (1999): Improvement of in vitro co-culture systems for bovine embryos using a low concentration of carbon dioxide and medium supplemented with $\beta$ mercaptoethanol. Theriogenology, 51, 551-558. 
19) Caamano, J.N., Ryoo, Z.Y. and Youngs, C.R. (1998) Promotion of development of bovine embryos produced in vitro by addition of cysteine and $\beta$-mercaptoethanol to a chemically defined culture system. J . Dairy Sci., 81, 369-374.

20) Takahashi, M., Nagai, T., Hamano, S., Kuwayama, M., Okamura, N. and Okano, A. (1993): Effect of thiol compounds on in vitro development and intracellular glutathione content of bovine embryos. Biol. Reprod., 49, 228-232.

21) Takahashi, M., Nagai, T., Okamura, N. and Okano, A. (1995): Effect of co-culture cells on the uptake of cystine into bovine embryos. Theriogenology, 43, 332 (abstr.). 